\title{
PROTOTIPE SISTEM OTOMASI GERBANG IRIGASI DENGAN IMPLEMENTASI MIKROKONTROLER BERBASIS IOT
}

\author{
Hari Sukmono', Nanda Kurnia Wardati', Sutikno \\ ${ }^{1}$ Teknik Elektro, Fakultas Teknik, Universitas Muhammadiyah Jember \\ Jl. Karimata 49 Jember 68121 \\ E-mail: hari.sukmono12@Gmail.com \\ ${ }^{2}$ Universitas Jember \\ J1. Kalimantan No.37 Jember 68121 \\ E-mail: 181920201006@students.unej.ac.id
}

\begin{abstract}
Abstrak - Irigasi adalah usaha untuk menyalurkan air dengan membuat bangunan dan saluran untuk mengalirkan air guna keperluan pertanian, membagikan air ke sawah dan ladang dengan cara yang teratur dan membuang air yang tidak diperlukan lagi. Proses irigasi yang dilakukan masih secara konvensional, karenanya perlu ditambahkan teknologi untuk mempermudah kinerja dan pemantau dengan mengembangkan sistem irigasi yang dikontrol secara otomatis oleh mikrokontroler dengan menambahkan sensor water flow sebagai pengukur debit air dan sensor ultrasonik untuk mengetahui tinggi air. Pada prototipe irigasi air menggunakan mikrokontroler Arduino Uno dan Wemos sebagai pemroses pada bagian perangkat dan terhubung ke Aplikasi Smartphone Android melalui koneksi internet atau biasa disebut dengan IOT (Internet Of Things), IOT memungkinkan aplikasi dapat terhubung pada semua perangkat untuk melakukan pengiriman data informasi ke petugas irigasi, sesuai dengan jadwal permintaan masyarakat kapan air itu dialirkan. perangkat bekerja berdasarkan jadwal yang telah ditentukan pada aplikasi android yang selanjutnya disimpan pada server untuk dibaca pada mikrokontroler, setelah perangkat selesai melakukan irigasi sesuai dengan jadwal, perangkat mengirimkan notifikasi pada Aplikasi dan mengirimkan data debit air serta tinggi air. Pada pengujian pengiriman data diperoleh rata-rata waktu untuk pengiriman data selama $1287 \mathrm{~ms}$.
\end{abstract}

Kata kunci: Internet Of Things, Otomasi Irigasi, Wemos, Water Flow

Copyright (C) 2019 Universitas Muhammadiyah Jember

\section{PENDAHULUAN}

Irigasi adalah upaya untuk menyalurkan, menyediakan, dan mengatur air guna keperluan pertanian dan perkebunan [1]. Dalam proses penyaluran irigasi masih banyak menggunakan cara manual. Contohnya, untuk menjalankan buka tutup gerbang irigasi petugas harus selalu datang ke area bendungan utama untuk membuka dan menutup saluran irigasi. Masih banyak kendala dengan menggunakan cara manual, perlu banyak tenaga untuk selalu membuka dan menutup gerbang irigasi dan diharuskan tertip dalam pembagian waktu irigasi. Tentunya hal ini kurang efektif dan praktis sehingga perlu mendapatkan sentuhan teknologi tepat guna dangan membuka dan menutup gerbang irigasi secara otomatis dari perintah penjadwalan melalui aplikasi android. Sistem kontrol otomatis ini dapat dibangun dari suatu mikrokontroller yang mampu menyimpan dan mengolah data sensor untuk menggerakkan pintu air [2].

Berdasarkan beberapa penelitian terkait gerbang irigasi yang telah dilakukan oleh Ahmad dkk [3]dan Siberan dkk [4], didapatkan kekurangan yaitu dalam penelitian tersebut tidak mengetahui data debit air yang masuk dari volume gerbang yang dibuka. Untuk mengatasi permasalahan tersebut, maka penulis melakukan penelitian untuk mengembangkan sistem irigasi yang dikontrol secara otomatis oleh mikrokontroler dengan menambahkan sensor waterflow. Penerapan dengan menambahkan sensor waterflow pada mikrokontroler untuk sistem irigasi agar dapat diketahui debit air yang masuk dari volume gerbang yang dibuka secara otomatis berdasarkan perintah yang diberikan. Tujuan dari penelitian ini yaitu mmerealisasikan prototipe sistem pengoperasian gerbang irigasi secara otomatis dan Untuk memudahkan mendapat informasi secara real time sebagaimana alat yang bekerja secara otomatis melalui penjadwalan di aplikasi android. 


\section{KAJIAN PUSTAKA}

Pada penelitian sebelumnya, telah dirancang prototipe buka tutup pintu bendungan otomatis berbasis IoT menggunakan sms gateway yang dilengkapi sensor water level untuk mengetahui tinggi level air [3]. Data tersebut kemudian di upload ke website secara rieal time. Kelebihan dari penelitian ini yaitu data yang dikirim bisa diakses melalui web dan data-data yang ditampilkan di website berbentuk grafik garis sehingga mudah untuk dianalisis. Namun penelitian ini juga memiliki kelemahan yaitu tidak memiliki aplikasi khusus yang dapat menerima data dengan notifikasi.

Pada penelitian lainnya yang berjudul "Perancangan Protipe Sistem Kontrol Pintu Air Irigasi Berbasis Android dan Jaringan Nirkabel", juga telah dirancang sistem buka tutup pintu air yang memiliki sistem kendali melalui relay untuk mengerakkan motor untuk membuka dan menutup pintu air [4]. Kelebihan dari penelitian ini yaitu menggunakan Uart WiFi yang berfungsi untuk mengirimkan data pada GSM Shield. Namun, kelemahan dari penelitian ini yaitu tidak dapat diktahui data debit air yang menggalir pada gerbang yang dibuka.

Berdasarkan kedua penelitian tersebut, maka dalam tugas akhir ini penulis akan mengembangkan "Prototipe Sistem Otomasi Gerbang Irigasi Dengan Implementasi Mikrokontroler." dengan menambahkan Modul Wemos D1 R2 sebagai media interkoneksi nirkabel, dan sensor Water Flow untuk mengetahui debit air yang mengalir dari volume gerbang yang dibuka. Berikut merupan peralatanperalatan yang digunakan pada penelitian ini:

\subsection{Mikrokontroler}

Board Arduino Uno adalah Hardware Mikrokontroler dengan rangkaian kecil yang memiliki chip untuk penyimpanan program yang telah ditentukan, arduino uno memiliki 14 pin digital dan 6 pin analog yang meliputi pin input dan output. Untuk dapat mengisi program ke chip arduino uno harus mengunakan aplikasi arduino IDE dengan menyambungkan kabel downloader ke port USB pada komputer dan arduino uno [5].

\subsection{Wemos D1 R2}

Wemos D1 R2 adalah mikrokontroler dengan chip ESP8266 sebuah mikrokontroler nirkabel (WiFi) 802.11 yang memiliki keserasian dengan Arduino IDE. Desain wemos D1 R2 didasarkan pada desain hardware Arduino standar. Wemos D1 R2 juga memiliki USB serial interface dengan kabel USB micro yang umum digunakan.

\subsection{Sensor Ultrasonik}

Sensor ultrasonik adalah sensor gelombang dari bunyi menjadi besaran listrik. Cara kerja sensor ultrasonik ini dengan memantulkan gelombang suara sehingga dapat diterjemahkan dalam tampilan jarak. Frekuensi bunyi gelombang ultrasonik sangat tinggi yaitu $20.000 \mathrm{~Hz}$ tetapi bunyi dari sensor ultrasonik tidak dapat didengar oleh telingan manusia. Bunyi sensor ultrasonik bisa menjalar melaui zat padat dan cair dan bunyi gelombang ultrasonik akan diserap oleh tekstil dan busa.

\subsection{Motor Servo}

Motor servo adalah hardware dengan memiliki serangkaian gear yang terhubung pada roda gigi motor dan dapat memperlambat pergerakan roda gigi lalu menimbulkan torsi motor servo, yang dapat diatur sudut dan derajat dari roda gigi keluaran motor.

\subsection{Water Flow Sensor G1/2}

Sensor water flow adalah sebuah hardware untuk mendeteksi laju aliran fluida. Yang berfunsi untuk mendeteksi aliran debit air, dengan bantuan baling-baling yang didorong oleh cairan dan mengerakkan potensiometer, yang menampilkan berupa data pulsa. Sensor ini hanya membutuhkan satu pin sinyal, pin 5V dan satu pin ground.

\subsection{Water Pump}

Water Pump adalah sebuah hardware energi mekanik dari mesin pengerak pompa menjadi energi tekan pada cairan yang dipompa. Water pump berfungsi untuk memindahkan air dari tempat yang renda ke tempat yang lebih tinggi.

\subsection{Relay}

Relay adalah Saklar / Switch yang dijalankan dengan bantuan listrik dengan komponen elektromekanikal, yang meiliki 2 bagian utama coil dan mekanikal. Prinsip kerja relay yaitu ketika coil dialiri arus listrik maka tuas akan tertarik karena adanya gaya eletromagnetik pada coil maka bok saklar akan menutup. 


\section{METODE PENELITIAN}

Tujuan dari pembuatan sebuah sistem otomatisasi untuk memudahkan mendapat informasi secara real time sebagaimana alat yang bekerja secara otomatis melalui penjadwalan diaplikasi android. Penelitian ini dilakukan dengan empat tahap proses yaitu analisis masalah, analisis kebutuhan, perancangan, implementasi, pengujian dan analisis sistem.

\subsection{Diagram Blok Sistem}

Dalam penelitian ini memiliki diagram blok sistem yang meliputi input, proses dan output, dengan mengaplikasikan ke prototipe ke bagian utama saluran primer, skunder dan tersier, apabila di saluran primer keadaan air full maka gebang akan membuka setengah dan apabila keadaan air rendah maka gerbang akan membuka full selanjutnya pada saluran skunder terbagi menjadi tiga bagian yang berfungsi untuk memmanajemen pembagian air secara teratur dari penjadwalan aplikasi android dan pada saluran tersier adalah saluran pembuangan, apabila pada saluran skunder melebihi batas maka air akan dialirkan ke saluran tersier.

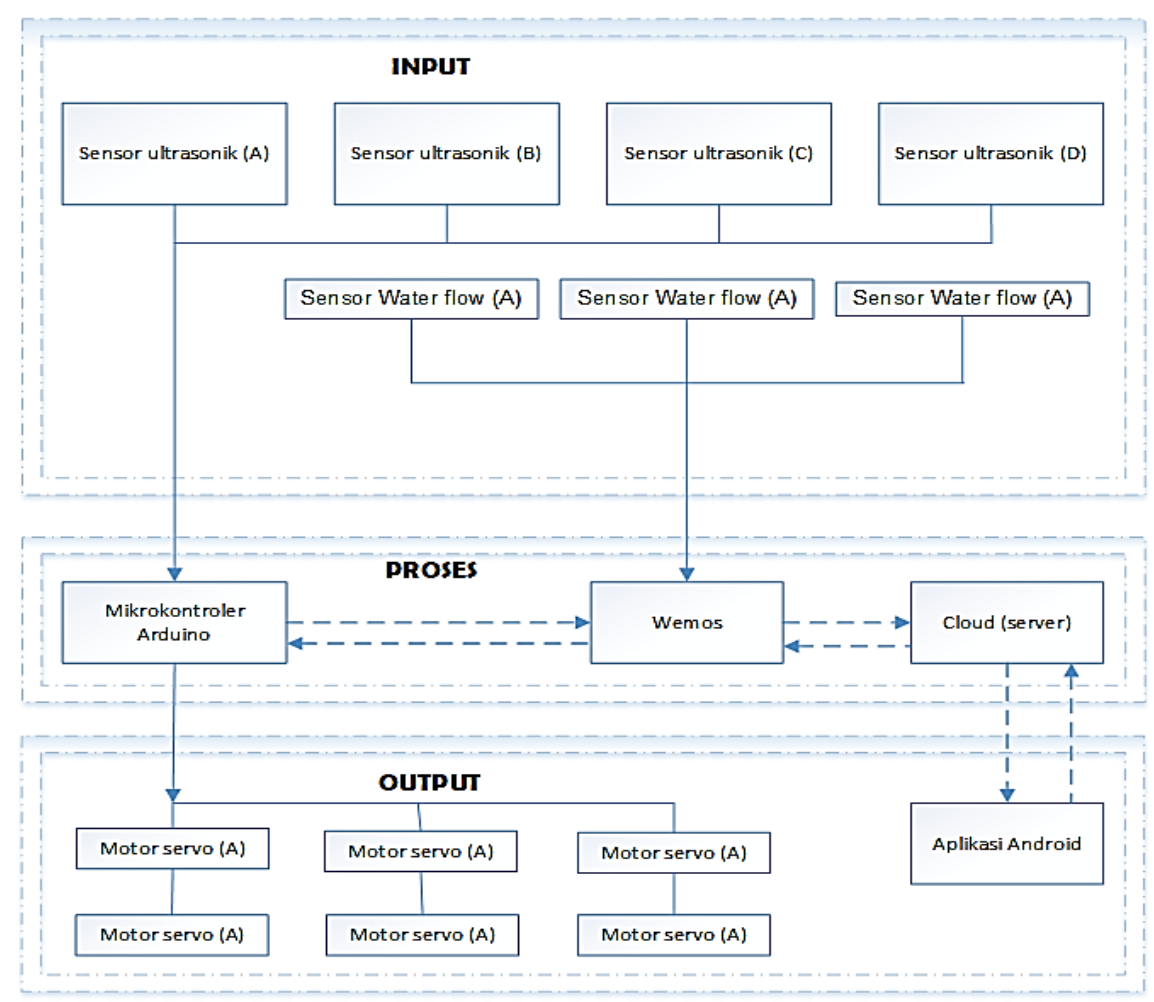

Gambar 1. Diagram Blok Sistem

\subsection{Diagram Alir}

Berikut adalah diagram alir yang meliputi proses alur kerja alat yang terbagi menjadi tiga bagian pada saluran primer, skunder dan tersier. diagram alir sistem kerja gerbang irigasi dengan menggunakan sensor Ultrasonik untuk mendeteksi ketinggian air pada Bak saluran primer, sekunder dan tersier. Sistem kerja sensor Ultrasonik perlu dilakukan pemrograman untuk menentukan parameter level air yang diinginkan. Setelah melakukan deklarasi perangkat membaca jadwal yang telah ditentukan melalui aplikasi android, jika jadwal terpenuhi maka perangkat akan melakukan esekusi buka gerbang sesuai jadwal jika perangkat sudah selesai melaksanakan jadwal perangkat akan megirimkan data ke data base. Tahapan perangkat saat melakukan jadwal irigasi :

1. Langkah pertama mengecek level air yang berada di bak saluran primer, jika level air $9 \mathrm{~cm}$ maka gerbang A pada saluran primer akan membuka setengah dan apabila level air $\geq 9 \mathrm{~cm}$ maka gerbang akan buka full.

2. Langkah yang kedua mengecek level air di saluran sekunder apabila level air $\leq 11 \mathrm{~cm}$ maka gerbang A pada saluran primer akan menutup.

3. Langkah yang ketiga mengecek level air pada saluran sekunder apabila terjadi peluapan air di saluran sekunder yang bernilai $\leq 11 \mathrm{~cm}$ maka gerbang pembuangan pada saluran sekunder akan 
membuka untuk membuang air dan menyetabilkan level air yang sudah ditentukan tinggi level air pada bak saluran sekunder.

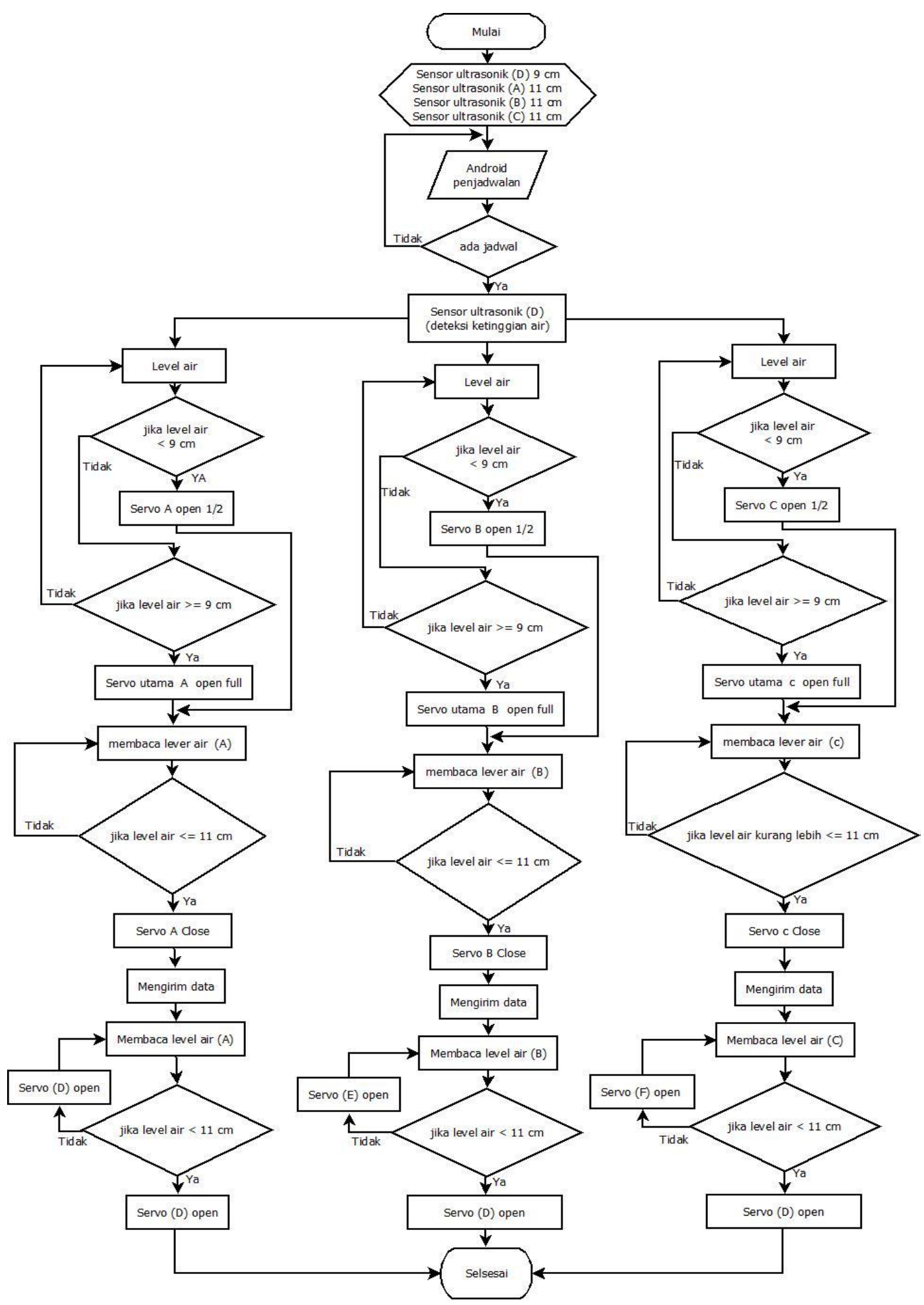

Gambar 2. Diagram Alir Penelitian 


\subsection{Desain Alat}

Berikut adalah desain alat yang memiliki dimensi P x L x T untuk panjang $32 \mathrm{~cm}$, lebar $19 \mathrm{~cm}$ dan untuk tinggi $17 \mathrm{~cm}$.

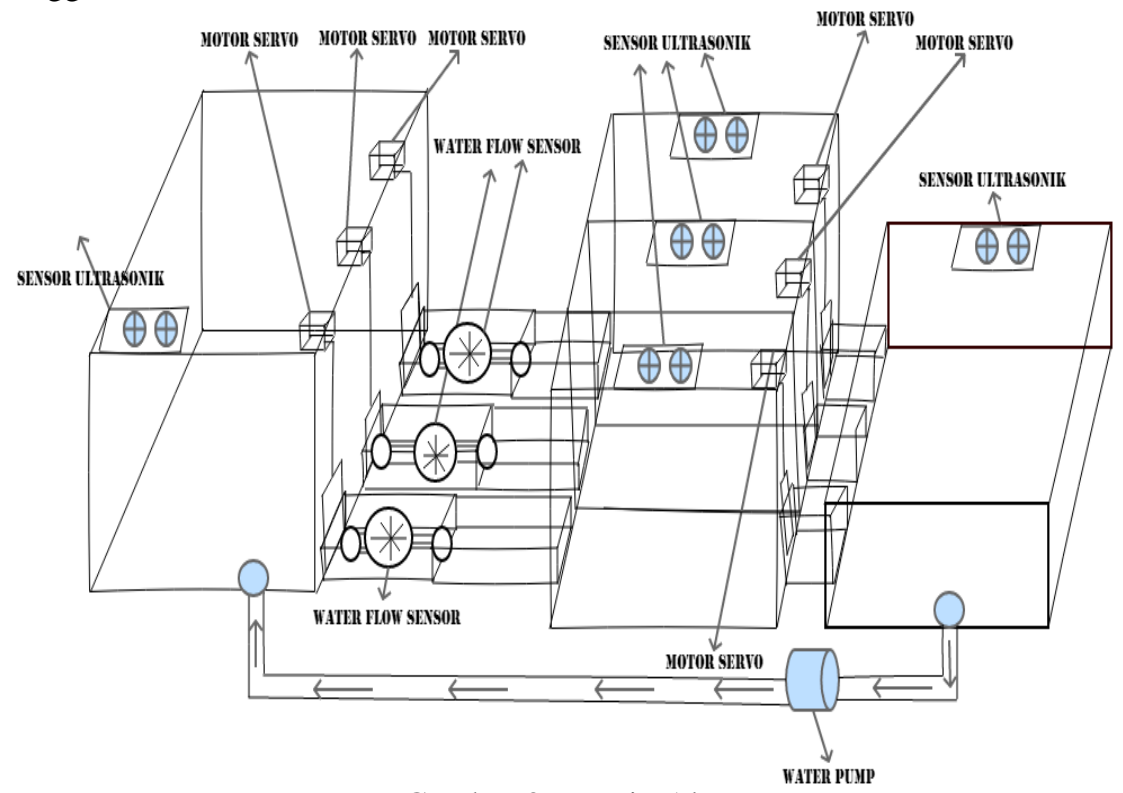

Gambar 3. Desain Alat

\subsection{Desain Aplikasi}

Berikut tempilan desain aplikasi pada android yang meliputi tampilan terkoneksi, tabel pengisian jadwal dan 3 informasi notifikasi yaitu selesai apabila alat sudah menjalankan perintah yang sudah ditentukan, mengirimkan debit air yang mengalir dan tinggi air.

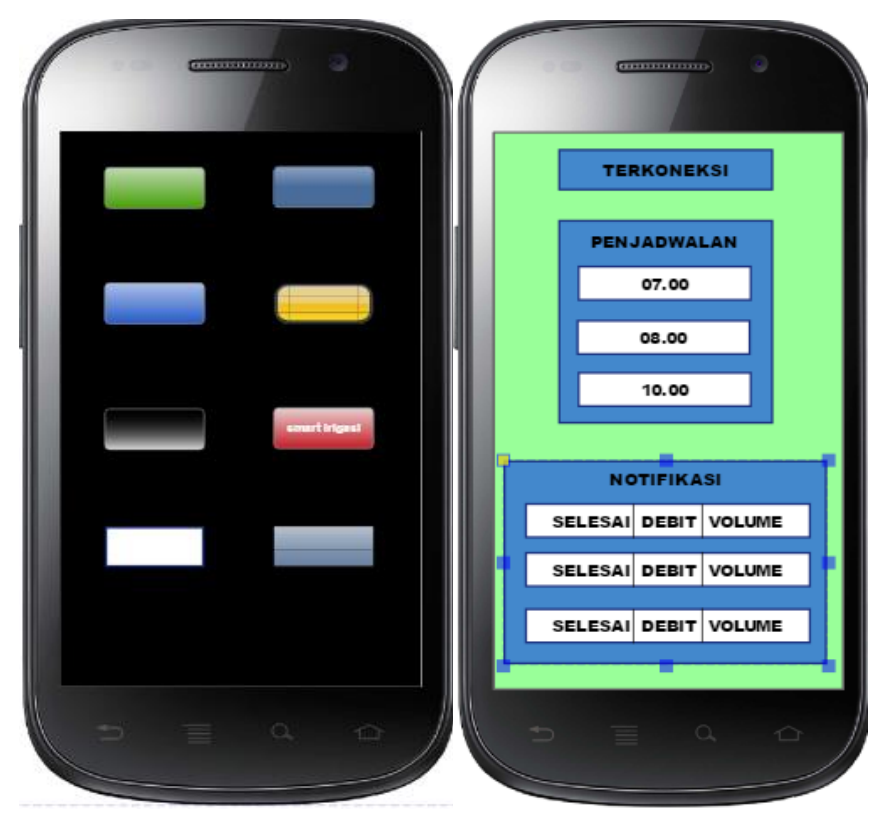

Gambar 4. Desain Aplikasi 


\section{HASIL DAN PEMBAHASAN}

\subsection{Pengujian Koneksi}

Pada pengujian koneksi data yang terkirim adalah data yang telah dijadwalkan sesuai gerbang yang dipilih, data tersebut ditampilkan pada tabel berikut:

Tabel 1. Pengujian Komunikasi Koneksi

\begin{tabular}{llll}
\hline NO & Update Data & $\begin{array}{l}\text { Data Masuk Dengan Kode, } \\
\text { dan Tinggi Level Air }(\mathbf{c m})\end{array}$ & $\begin{array}{l}\text { Keterangan Didapat Data Yang } \\
\text { Dikirimkan Secara real time }\end{array}$ \\
\hline 1 & Gerbang : B & B, 9,00 & Berhasil \\
\hline
\end{tabular}

\subsection{Pengujian Delay Koneksi}

Pada pengujian koneksi memiliki delay waktu dengan satuan nilai mili second, delay tersebut ditampilkan pada tabel berikut:

Tabel 2. Pengujian Delay Koneksi

\begin{tabular}{llllll}
\hline NO & Wifi & $\begin{array}{l}\text { IP address } \\
\text { Wemos }\end{array}$ & $\begin{array}{l}\text { Waktu } \\
\text { Koneksi } \\
(\mathbf{m s})\end{array}$ & $\begin{array}{l}\text { Data Tanggal, Bulan } \\
\text { dan Tahun }\end{array}$ & Keterangan \\
\hline 1 & Connected & 192.168 .43 .67 & 20501 & 28 jan 2020 & Berhasil \\
\hline
\end{tabular}

\subsection{Pengujian Uploadd Data}

Pada pengujian selanjutnya adalah pengujian tentang watu upload data yang dikirimkan ke aplikasi android berupa notifikasi, waktu upload data tersebut ditampilkan pada gambar berikut:

Tabel 3. Pengujian Delay Upload Data

\begin{tabular}{lllll}
\hline NO & $\begin{array}{l}\text { Data Masuk Dengan } \\
\text { Kode dan Tinggi Level } \\
\text { Air }(\mathbf{c m})\end{array}$ & $\begin{array}{l}\text { Waktu Upload } \\
\text { Data (ms) }\end{array}$ & $\begin{array}{l}\text { Data Tanggal, Bulan } \\
\text { dan Tahun }\end{array}$ & Keterangan \\
\hline 1 & B, 9,00 & 1287 & 28 jan 2020 & Berhasil \\
\hline
\end{tabular}

\subsection{Pengujian Pengiriman Data Sinyal Servo}

Pada pengujian selanjutnya adalah pengujian tentang watu upload data yang dikirimkan ke aplikasi android berupa notifikasi, waktu upload data tersebut ditampilkan pada gambar berikut:

Tabel 4. Pengujian Pengiriman Data Sinyal Servo

\begin{tabular}{lllll}
\hline NO & $\begin{array}{l}\text { Data Nilai Sinyal } \\
\text { Servo Pada } \\
\text { Gerbang (A) }\end{array}$ & $\begin{array}{l}\text { Data Nilai Sinyal } \\
\text { Servo Pada Gerbang } \\
(\text { B })\end{array}$ & $\begin{array}{l}\text { Data Nilai } \\
\text { Sinyal Servo } \\
\text { Pada Gerbang } \\
(\text { C) }\end{array}$ & $\begin{array}{l}\text { Keterangan Didapat Data } \\
\text { Yang Dikirimkan Secara } \\
\text { real time }\end{array}$ \\
\hline 1 & 1 & 0 & 1 & Berhasil \\
\hline
\end{tabular}

\subsection{Pengujian Sistem}

Pada pengujian sistem yang pertama berada disalurkan irigasi primer. Pengujian sistem ini dilakukan dengan 5 pengujian yang bertujuan untuk mengetahui rata-rata error dengan menampilkan angka hasil pengukuran manual dan dengan pengukuran sensor yang ditampilkan pada tabel berikut:

Tabel 5. Pengujian Sensor Ultrasonik (Saluran Irigasi A)

\begin{tabular}{llllll}
\hline No & Pengujian & $\begin{array}{l}\text { Jarak } \\
\text { Sebenarnya }(\mathbf{c m})\end{array}$ & $\begin{array}{l}\text { Jarak } \\
\text { Terdeteksi } \\
(\mathbf{c m})\end{array}$ & Error (\%) & Keterangan \\
\hline $\mathbf{1}$ & Pengujian 1 & 18,10 & 17,88 & 1,21 & Berhasil \\
$\mathbf{2}$ & Pengujian 2 & 14,80 & 14,76 & 0,27 & Berhasil \\
$\mathbf{3}$ & Pengujian 3 & 12,90 & 12,68 & 1,70 & Berhasil \\
$\mathbf{4}$ & Pengujian 4 & 11,30 & 11,17 & 1,15 & Berhasil \\
$\mathbf{5}$ & Pengujian 5 & 6,30 & 6,26 & 0,63 & Berhasil \\
\hline \multicolumn{2}{l}{ Total rata-rata error } & & & 0,992 & \\
\hline
\end{tabular}




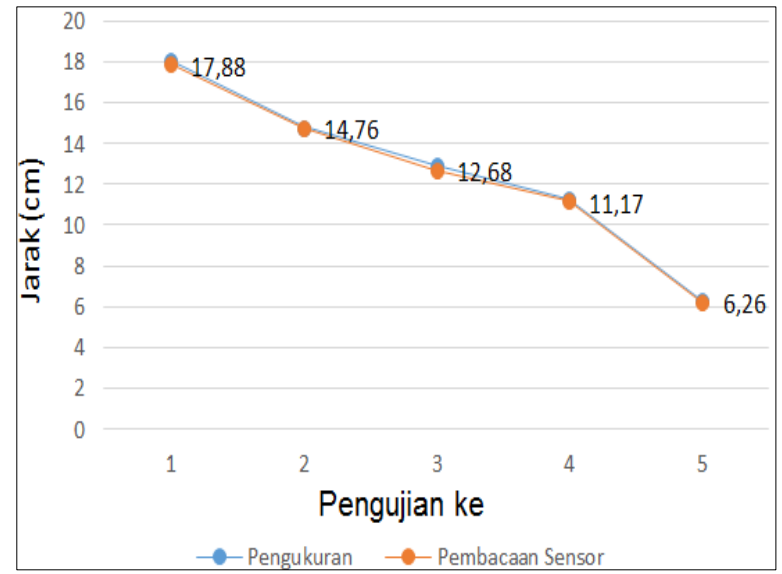

Gambar 5. Grafik Pengujian Sensor A

Pada pengujian sistem yang kedua berada disalurkan irigasi sekunder pada saluran irigasi B. Pengujian sistem ini dilakukan dengan 5 pengujian yang bertujuan untuk mengetahui rata-rata error dengan menampilkan angka hasil pengukuran manual dan dengan pengukuran sensor yang ditampilkan pada tabel berikut:

Tabel 6. Pengujian Sensor Ultrasonik (Saluran Irigasi B)

\begin{tabular}{llllll}
\hline No & Pengujian & $\begin{array}{l}\text { Jarak } \\
\text { Sebenarnya } \\
(\mathbf{c m})\end{array}$ & $\begin{array}{l}\text { Jarak } \\
\text { Terdeteksi } \\
(\mathbf{c m})\end{array}$ & Error $(\%)$ & Keterangan \\
\hline 1 & Pengujian 1 & 14,50 & 14,41 & 0,62 & Berhasil \\
2 & Pengujian 2 & 12,70 & 12,57 & 1,02 & Berhasil \\
3 & Pengujian 3 & 11,15 & 11,12 & 0,26 & Berhasil \\
4 & Pengujian 4 & 9,30 & 9,20 & 1,07 & Berhasil \\
5 & Pengujian 5 & 8,30 & 8,18 & 1,44 & Berhasil \\
\hline Total rata-rata error & & & 0,882 & \\
\hline
\end{tabular}

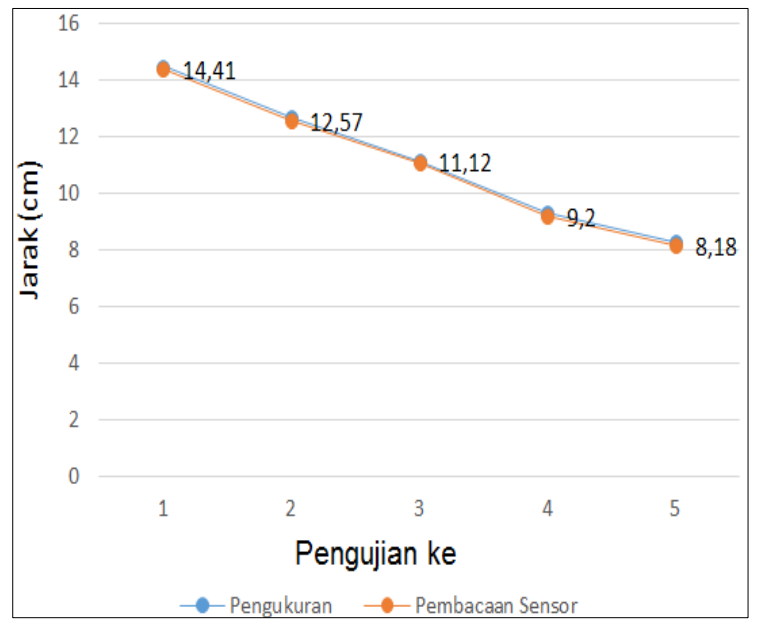

Gambar 6. Grafik Pengujian Sensor B

Pada pengujian sistem yang ketiga berada disalurkan irigasi sekunder pada saluran irigasi C. Pengujian sistem ini dilakukan dengan 5 pengujian yang bertujuan untuk mengetahui rata-rata error dengan menampilkan angka hasil pengukuran manual dan dengan pengukuran sensor yang ditampilkan pada tabel berikut: 
Tabel 7. Pengujian Sensor Ultrasonik (Saluran Irigasi C)

\begin{tabular}{llllll}
\hline No & Pengujian & $\begin{array}{l}\text { Jarak Sebenarnya } \\
(\mathbf{C m})\end{array}$ & $\begin{array}{l}\text { Jarak } \\
\text { Terdeteksi } \\
(\mathbf{C m})\end{array}$ & Error (\%) & Keterangan \\
\hline 1 & Pengujian 1 & 14,60 & 14,40 & 1,36 & Berhasil \\
2 & Pengujian 2 & 12,50 & 12,43 & 0,56 & Berhasil \\
3 & Pengujian 3 & 11,90 & 11,67 & 1,93 & Berhasil \\
4 & Pengujian 4 & 9,40 & 9,36 & 0,42 & Berhasil \\
5 & Pengujian 5 & 8,20 & 8,10 & 0,24 & Berhasil \\
\hline \multicolumn{7}{l}{ Total Rata-Rata Error } & & 0,902 & \\
\hline
\end{tabular}

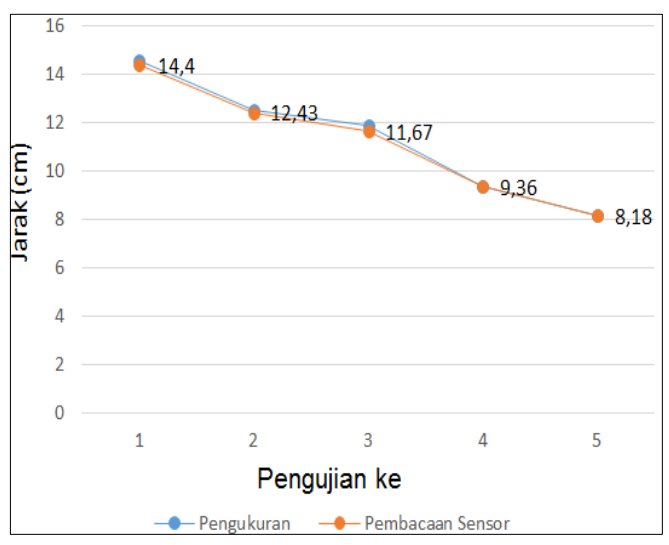

Gambar 7. Grafik Pengujian Sensor C

Pada pengujian sistem yang keempat berada disalurkan irigasi sekunder pada aluran irigasi D. Pengujian sistem ini dilakukan dengan 5 pengujian yang bertujuan untuk mengetahui rata-rata error dengan menampilkan angka hasil pengukuran manual dan dengan pengukuran sensor yang ditampilkan pada tabel berikut:

Tabel 8. Pengujian Sensor Ultrasonik (Saluran Irigasi D)

\begin{tabular}{llllll}
\hline No & Pengujian & $\begin{array}{l}\text { Jarak Sebenarnya } \\
(\mathbf{c m})\end{array}$ & $\begin{array}{l}\text { Jarak } \\
\text { Terdeteksi } \\
(\mathbf{c m})\end{array}$ & Error (\%) & Keterangan \\
\hline 1 & Pengujian 1 & 14,70 & 14,68 & 0,13 & Berhasil \\
2 & Pengujian 2 & 12,40 & 12,32 & 0,64 & Berhasil \\
3 & Pengujian 3 & 11,20 & 11,18 & 0,17 & Berhasil \\
4 & Pengujian 4 & 9,60 & 9,45 & 1,56 & Berhasil \\
5 & Pengujian 5 & 8,90 & 8,85 & 0,50 & Berhasil \\
\hline \multicolumn{7}{l}{ Total rata-rata error } & & 0,6 & \\
\hline
\end{tabular}

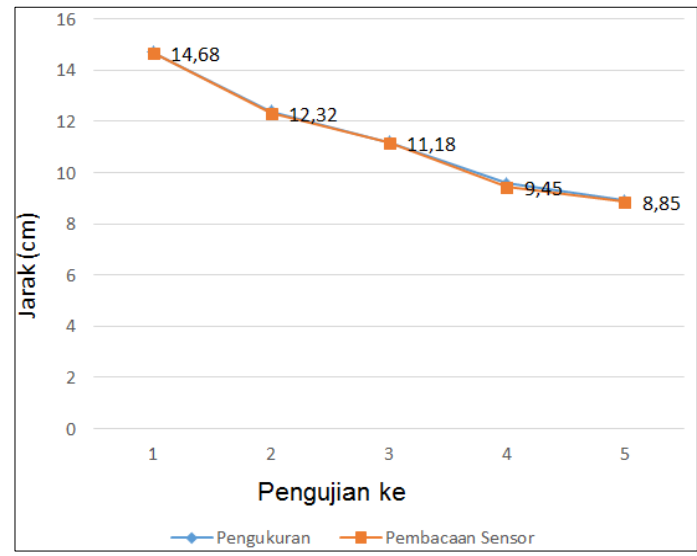

Gambar 8. Grafik Pengujian Sensor D 
Pada pengujian sistem yang kelima berada disalurkan irigasi tersier. Pengujian sistem ini dilakukan dengan 5 pengujian yang bertujuan untuk mengetahui rata-rata error dengan menampilkan angka hasil pengukuran manual dan pengukuran sensor yang ditampilkan pada tabel berikut:

Tabel 9. Pengujian Sensor Ultrasonik (Saluran Irigasi E)

\begin{tabular}{llllll}
\hline No & Pengujian & $\begin{array}{l}\text { Jarak } \\
\text { Sebenarnya } \\
(\mathbf{c m})\end{array}$ & $\begin{array}{l}\text { Jarak } \\
\text { Terdeteksi } \\
(\mathbf{c m})\end{array}$ & Error $(\boldsymbol{\%})$ & Keterangan \\
\hline 1 & Pengujian 1 & 10,80 & 10,75 & 0,46 & Berhasil \\
2 & Pengujian 2 & 8,50 & 8,47 & 0,35 & Berhasil \\
3 & Pengujian 3 & 6,40 & 6,30 & 1,56 & Berhasil \\
4 & Pengujian 4 & 5,18 & 5,12 & 1,15 & Berhasil \\
5 & Pengujian 5 & 2,60 & 2,58 & 0,76 & Berhasil \\
\hline
\end{tabular}

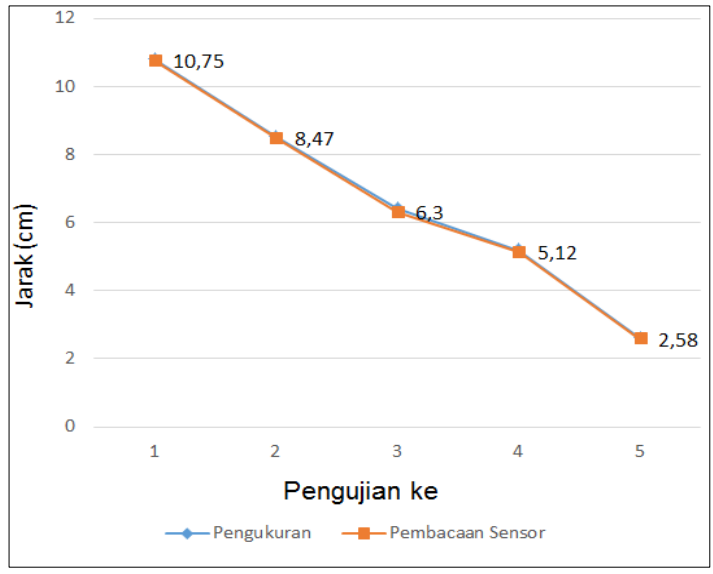

Gambar 9. Grafik Pengujian Sensor E

Pada pengujian sistem buka tutup gerbang disalurkan irigasi primer memiliki 2 kondisi buka setengah dan buka full. Pengujian sistem ini dilakukan dengan 2 pengujian yang bertujuan untuk mengetahui keberhasilan buka tutup gerbang dengan pembacaan sensor ultrasonik sebagai acuan buka tutup gerbang otomatis oleh servo yang ditampilkan pada tabel berikut:

Tabel 10. Pengujian Servo Motor Buka Tutup Gerbang (Saluran Irigasi A, B, C)

\begin{tabular}{lllll}
\hline No & Gerbang & $\begin{array}{l}\text { Pembacaan } \\
\text { Sensor }\end{array}$ & Kondisi & Keterangan \\
\hline 1 & Gerbang A & $<9 \mathrm{~cm}$ & Servo Open Setengah & Berhasil \\
2 & Gerbang A & $>=9 \mathrm{~cm}$ & Servo Open Full & Berhasil \\
3 & Gerbang A & $<=11 \mathrm{~cm}$ & Servo A Close & Berhasil \\
4 & Gerbang B & $<9 \mathrm{~cm}$ & Servo Open Setengah & Berhasil \\
5 & Gerbang B & $>=9 \mathrm{~cm}$ & Servo Open Full & Berhasil \\
6 & Gerbang B & $<=11 \mathrm{~cm}$ & Servo Close & Berhasil \\
7 & Gerbang C & $<9 \mathrm{~cm}$ & Servo Open Setengah & Berhasil \\
8 & Gerbang C & $>=9 \mathrm{~cm}$ & Servo Open Full & Berhasil \\
\hline 9 & Gerbang C & $<=11 \mathrm{~cm}$ & Servo Close & Berhasil \\
\hline
\end{tabular}

Pada pengujian sistem buka tutup gerbang disalurkan irigasi sekunder pada gerbang D,E,F memiliki 2 kondisi buka setengah dan buka full. Pengujian sistem ini dilakukan dengan 2 pengujian yang bertujuan untuk mengetahui keberhasilan buka tutup gerbang dengan pembacaan sensor ultrasonik sebagai acuan buka tutup gerbang otomatis oleh servo yang ditampilkan pada tabel berikut:

Tabel 11. Pengujian Servo Motor Buka Tutup Gerbang (Saluran Irigasi D, E, F)

\begin{tabular}{lllll}
\hline No & Gerbang & Pembacaan Sensor & Kondisi & Keterangan \\
\hline 1 & Gerbang D & $<11 \mathrm{~cm}$ & Servo Open Full & Berhasil \\
2 & Gerbang E & $<11 \mathrm{~cm}$ & Servo Open Full & Berhasil \\
3 & Gerbang F & $<11 \mathrm{~cm}$ & Servo Open Full & Berhasil \\
\hline
\end{tabular}


Pada pengujian sistem debit air dengan sensor Water flow yang berada setelah saluran irigasi primer pada gerbang A,B,C memiliki fungsi untuk membaca debit air pada volume gerbang yang dibuka. Pengujian sistem ini dilakukan dengan 3 pengujian yang bertujuan untuk mengetahui keberhasilan perhitungan debit air dengan pembacaan sensor Water Flow sebagai acuan data yang akan dikirimkan ke android yang ditampilkan pada tabel berikut:

Tabel 12. Hasil Pengujian Pelaksanaan Jadwal

\begin{tabular}{lllll}
\hline No & Pengujian & $\begin{array}{l}\text { Pembacaan Sensor } \\
\text { Debit Air }(\mathbf{L} / \mathbf{s})\end{array}$ & Tinggi Air $(\mathbf{c m})$ & Keterangan \\
\hline 1 & Pengujian 1 Gerbang A & 0,75 & 9 & Berhasil \\
2 & Pengujian 2 Gerbang B & 2,51 & 9 & Berhasil \\
3 & Pengujian 3 Gerbang C & 2,35 & 9 & Berhasil \\
4 & Pengujian 4 Gerbang A & 24,5 & 9 & Berhasil \\
5 & Pengujian 5 Gerbang B & 24,1 & 9 & Berhasil \\
6 & Pengujian 6 Gerbang C & 24,4 & 9 & Berhasil \\
7 & Pengujian 7 Gerbang A & 0,07 & 9 & Berhasil \\
8 & Pengujian 8 Gerbang B & 2,02 & 9 & Berhasil \\
9 & Pengujian 9 Gerbang C & 2,66 & 9 & Berhasil \\
10 & Pengujian 10 Gerbang A & 24,5 & 9 & Berhasil \\
\hline
\end{tabular}

Pada pengujian sistem debit air dengan sensor Water flow yang dilakukan secara 3 kali. Pengujian sistem ini bertujuan untuk mengetahui tingkat keberhasilan perhitungan debit air dengan pembacaan sensor Water Flow pada pencobaan 1 (1000 mili liter), percobaan 2 (500 mili liter) dan percobaan 3 (400 mili liter) yang ditampilkan pada tabel berikut:

Tabel 13. Hasil Pengujian Sensor Water Flow

\begin{tabular}{llllllll}
\hline \multirow{2}{*}{ NO } & $\begin{array}{l}\text { Volume } \\
\text { Asli }(\mathbf{m l})\end{array}$ & $\begin{array}{l}\text { Volume } \\
\text { Ukur }(\mathbf{m l})\end{array}$ & $\begin{array}{l}\text { Waktu } \\
(\mathbf{m s})\end{array}$ & $\begin{array}{l}\text { Hasil } \\
\text { Hitung }\end{array}$ & $\begin{array}{l}\text { Max Debit } \\
(\mathbf{L} / \mathbf{s})\end{array}$ & $\begin{array}{l}\text { Error } \\
(\boldsymbol{\%})\end{array}$ & Keterangan \\
& & $\mathbf{( L / s )}$ & & \\
\hline 1 & 1000 & 1024 & 27027 & 0,0379 & 0,044 & 2,4 & Berhasil \\
2 & 500 & 504 & 11011 & 0,0457 & 0,051 & 0,8 & Berhasil \\
3 & 400 & 412 & 20021 & 0,02057 & 0,029 & 3,0 & Berhasil \\
\hline \multicolumn{7}{l}{ Total rata-rata error } \\
\hline
\end{tabular}

\section{KESIMPULAN}

Berikut adalah kesimpulan dari penelitian yang telah dilakukan, yaitu;

1. Berdasarkan hasil pengujian Perangkat dapat mengontrol prototipe gerbang irigasi air serta membaca tinggi level air dan debit air pada saat proses irigasi. Perangkat dapat menutup gerbang ketika jadwal tidak terpenuhi ataupun jadwal irigasi sudah dilaksanakan ketika pada jalur irigasi terdapat air yang melebihi batas, gerbang pembuangan air dapat membuka secara otomatis. Dalam pembacaan sensor ultrasonik diperoleh persentase keberhasilan sebesar $99,0 \%$ pada saluran irigasi A, 99,1\% pada saluran irigasi B, 99,0\% pada saluran irigasi C, 99,4\% pada saluran irigasi D dan $99,1 \%$ pada saluran irigasi E. Pada pembacaan sensor water flow diperoleh persentase keberhasilan sebesar 97,9\%.

2. Berdasarkan hasil pengujian pada bagian aplikasi android dapat menerima data dari server untuk ditampilkan pada aplikasi. Untuk pengaturan jadwal dapat dilakukan selama android mendapat koneksi internet dan mengirimkan jadwal pada server. Perangkat dapat menerima notifikasi ketika jadwal irigasi telah terpenuhi. Pada pengujian pengiriman data diperoleh rata-rata waktu untuk pengiriman data selama $1287 \mathrm{~ms}$. 


\section{REFERENSI}

[1] A. Wijaya and M. Rivai, "Monitoring dan Kontrol Sistem irigasi Berbasis IoT Menggunakan Banana PI," J. Tek. ITS, vol. 7, no. 2, pp. A288-A922, 2018, doi: 10.12962/j23373539.v7i2.31113.

[2] F. E. Laumal, E. P. Hattu, and K. B. N. Nope, "Pengembangan Pintu Air Irigasi Pintar berbasis Arduino untuk Daerah Irigasi Manikin,” J. Rekayasa Elektr., vol. 13, no. 3, pp. 139-144, 2017, doi: 10.17529/jre.v13i3.8505.

[3] Basyarudin, "Perancangan Prototipe Sistem Kontrol Pintu Air Irigasi Berbasis Android dan Jaringan Nirkabel," Infotek J. Inform. dan Teknol., vol. 2, no. 2, pp. 115-121, 2018, doi: 10.29408/jit.v2i1.905.

[4] Saberan, A. N. Asyikin, A. A. Putra, A. Kukuh, A. Saputro, and R. Wahyudi, "Rancang Bangun Prototipe Buka Tutup Pintu Menggunakan Sms Gateway," vol. 10, no. 1, pp. 18-24, 2018, doi: 10.31961/porosteknik.v10i1.659.

[5] S. J. Sokop, D. J. Mamahit, and S. R. U. A. Sompie, "Trainer Periferal Antarmuka Berbasis Mikrokontroler Arduino Uno," E-Journal Tek. Elektro Dan Komput., vol. 5, no. 3, pp. 13-23, 2016, doi: 10.35793/jtek.5.3.2016.11999.

\section{BIOGRAFI PENULIS}

\begin{tabular}{|l|l|} 
Hari Sukmono, Mahasiswa Program Studi Teknik Elektro Universitas Muhammadiyah \\
Jember. Topik penelitiannya berkaitan dengan arus lemah.
\end{tabular} \mid $\begin{aligned} & \text { Sutikno, merupakan lulusan S1 Teknik Elektro di Universitas Muhammadiyah Jember dan } \\
& \text { lulus pada tahun 2017, sekarang aktif sebagai tenaga laboran Teknik Elektro UM Jember. } \\
& \text { Penulis melanjutkan pendidikan Magister Teknik Elektro di Universitas Jember. }\end{aligned}$

